\title{
LARGE RAPTORIAL BIRDS AS ENEMIES OF CICADAS
}

\author{
By Charres T. Brues
}

\section{Harvard University}

Cicadas form an important source of food for many carnivorous birds. There are abundant published records which attest the fondness of a great variety of birds for these large Homoptera which constitute a notable part of the insect fauna over many extensive areas throughout the world.

By reason of its periodical appearance in immense swarms, the North American Magicicada septendecim is naturally eaten in large numbers by a great variety of insectivorous birds on the rare occasions that it appears. Extensive records collated by Marlatt, Myers and McAttee ${ }^{1}$ show that this cicada, as well as many others, frequently forms a part of the avian diet.

It is usually the smaller and less powerful species of birds which prey on cicadas, but often some of the larger raptorial Falconidae do not disdain to capture and eat them with apparent relish. An early account of kites feeding on cicadas in the American tropics is contained in Belt's "Naturalist in Nicaragua" published in 1874 (p. 230), where he found on dissection that their crops were filled with these insects. Later, in India, Distant, and also Bingham noted similar birds preying on cicadas and Myers (loc. cit.) quotes Australian records of similar occurrences.

During our recent stay in the Philippines we had the opportunity to observe the frequent capture of a very large cicada (Cryptotympana acuta Sign.) that was common during the summer months (May and June) in the wooded foot-hills above Dumaguete on Negros Island. I am indebted to my friend, Dr. Z. P. Metcalf for the specific determination. The cicadas could be seen frequently resting in numbers among the smaller branches of trees, and at frequent intervals one or several soaring kites would appear, circle among the high trees and pick off the immobile insects. ${ }^{2}$ At this season the shrill din of the singing insects was very pronounced and

${ }^{1}$ Marlatt, C. L. The Periodical Cicada. Bull. U. S. Dept. Agric., n. s. No. 14 (1878). Myers, J. G. Insect Singers. G. Rutledge \& Sons, London (1929). McAttee, W. L. Effectiveness in Nature of the So-called Adaptations of animals Chiefly as Illustrated by the Food Habits of Nearctic Birds. Smithsonian Misc. Coll., vol 85, No. 7 (1932).

${ }^{2}$ The identification of the birds is not positive, but they were, without much question, the common honey buzzard (Pernis ptilorhynchus). 
the capture of one or two specimens was accomplished so adroitly that there was no interruption in the rhythm of the chorus. Occasionally a cicada would let out a piercing shriek as the bird's beak closed upon it, and instantly the whole assemblage lapsed into silence for a time while the kites drifted away. When picked up in the fingers the cicadas behave similarly with a sudden vocal outburst of unbelievable vigor, or if one is captured by a large mantis its prolonged swan-song assumes deafening proportions. Neither the mantises nor larger birds give any indication that they notice such outbursts, although they must have some protective value against smaller birds. In my own experience, the cicadas of more temperate regions do not respond so loudly to rough handling, particularly the periodical cicada which is very docile in this respect.

Although the actual capture of the cicadas by kites must depend upon sight, the preliminary approach of the birds to the trees is probably influenced by the shrill and incessant singing of the insects since the birds lose interest during temporary lulls in the chorus. 

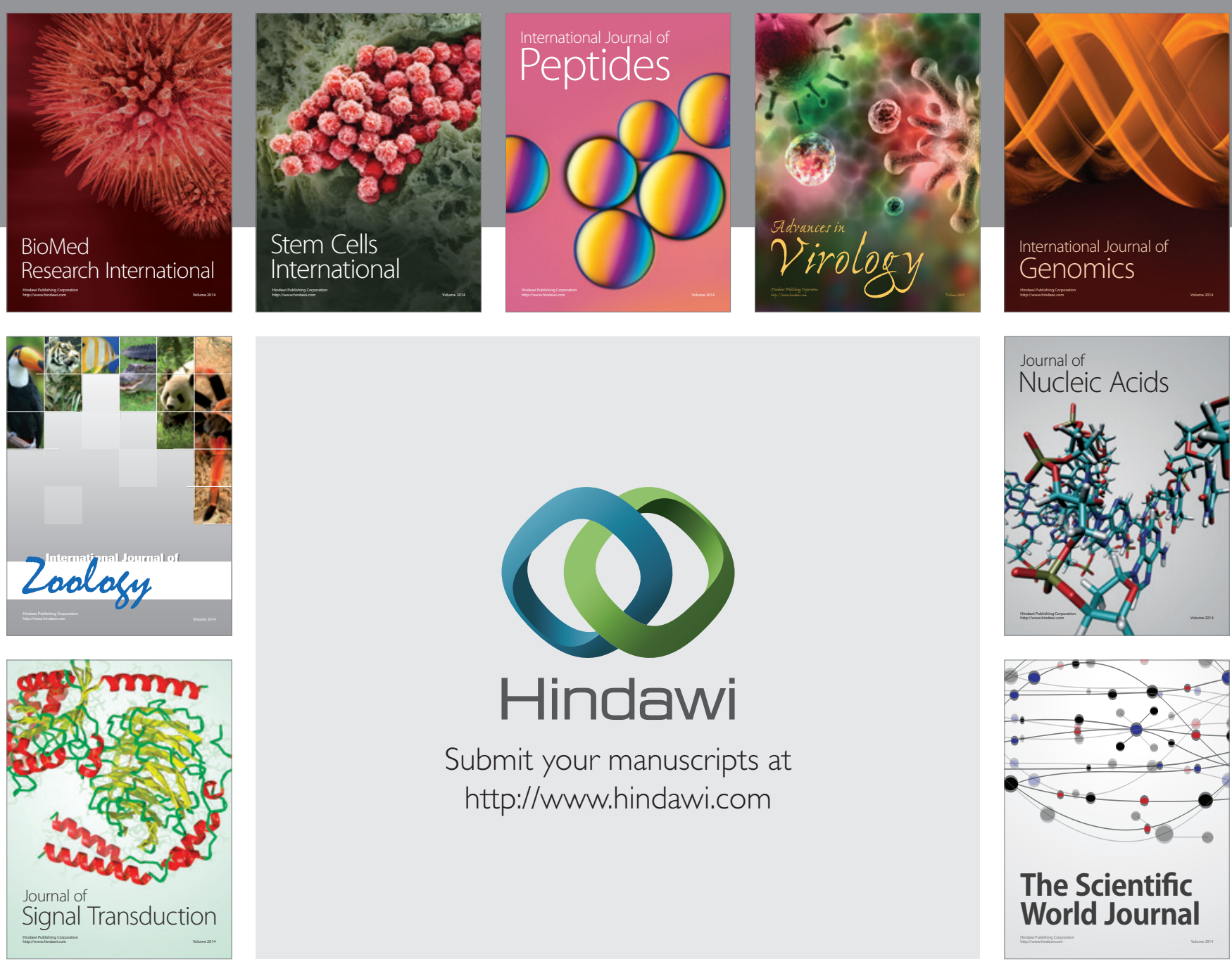

Submit your manuscripts at

http://www.hindawi.com
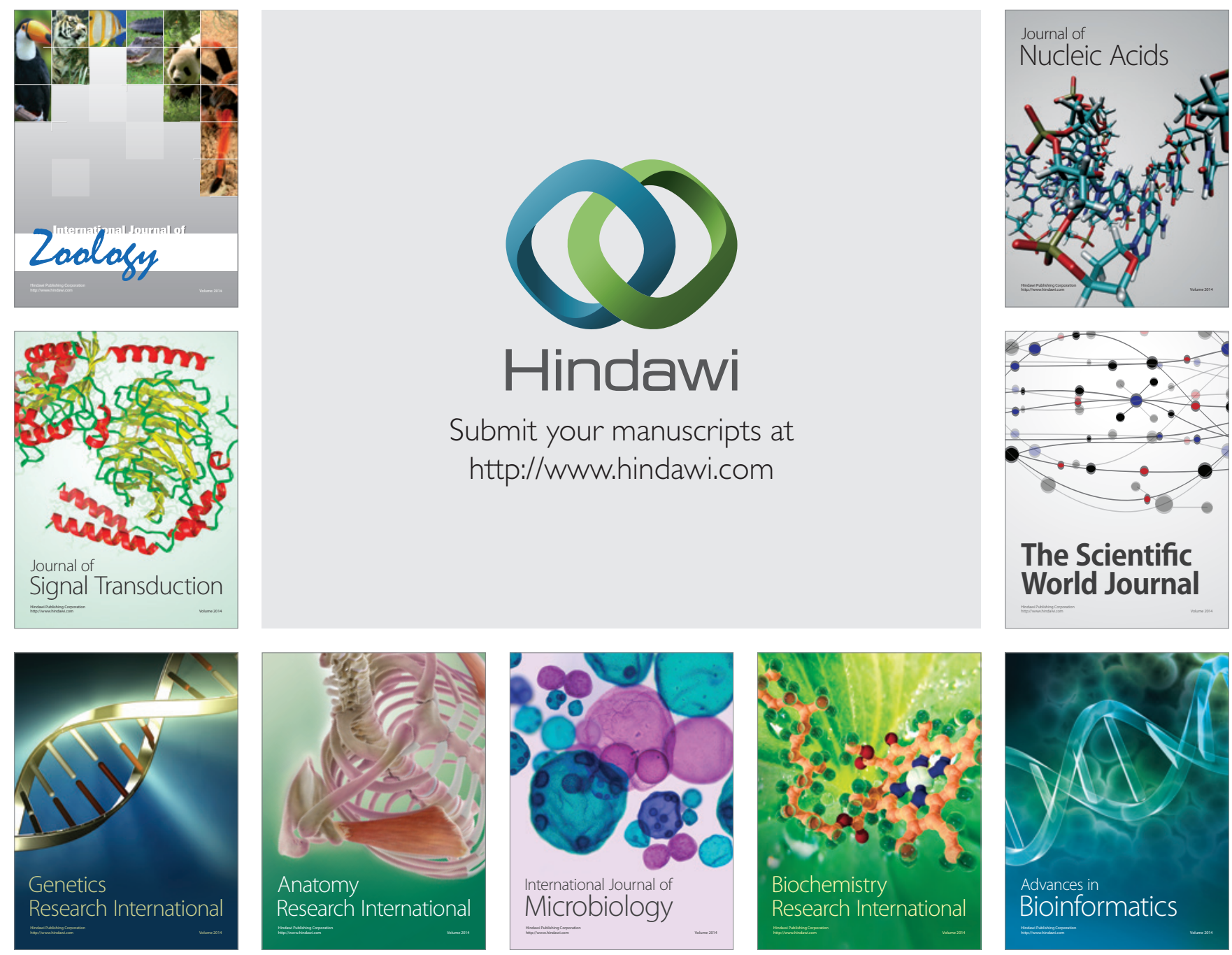

The Scientific World Journal
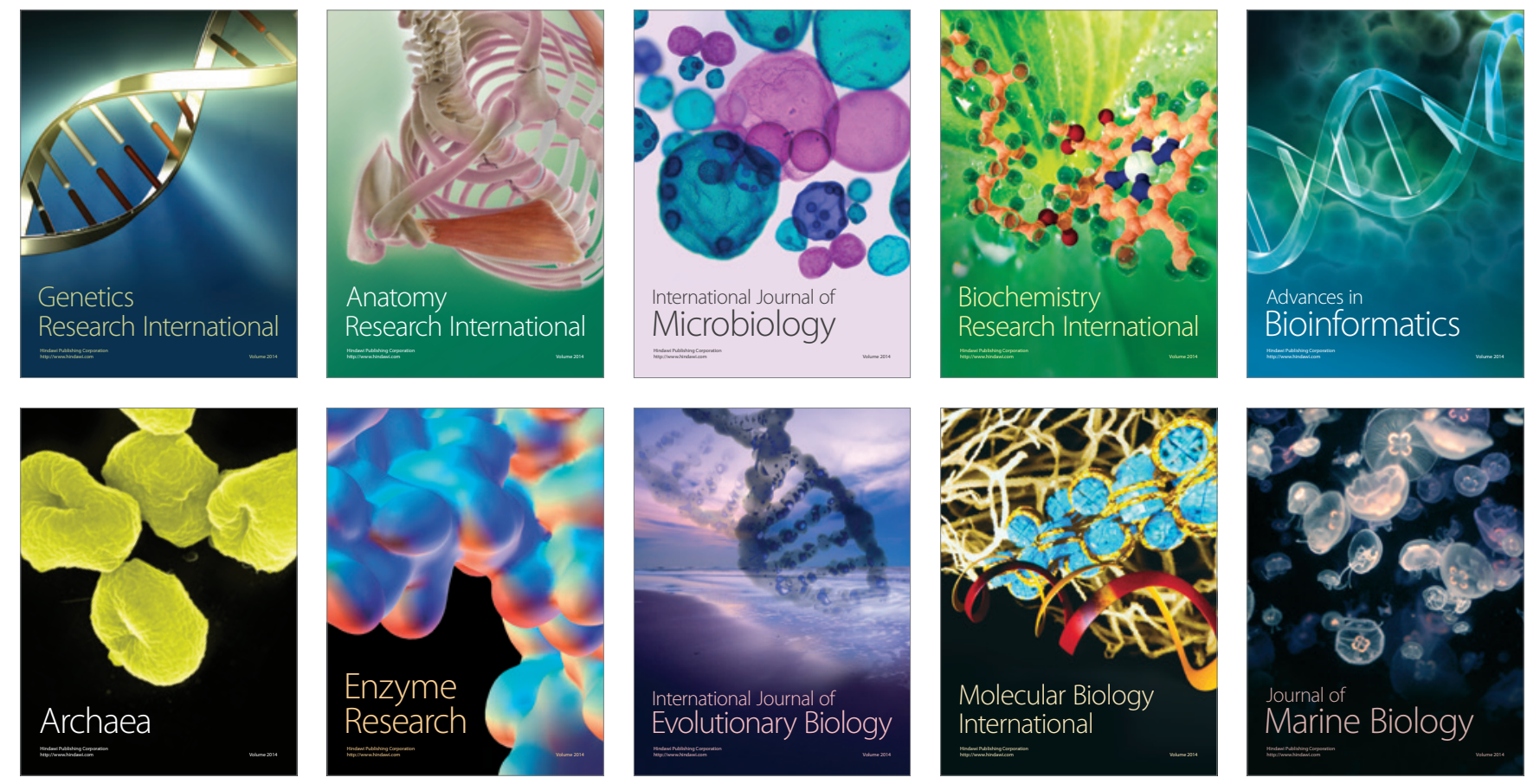